\title{
Generaciones futuras Y PERSONALIDAD JURÍDICA
}

\author{
Future Generations \\ and Legal Personality
}

Gerações futuras E PERSONALIDADE JURÍDICA

La Tierra proporciona suficientes recursos para satisfacer las necesidades de todos los hombres, pero no la codicia de todos los hombres.

El hombre no posee el poder de crear vida. Por consiguiente, tampoco posee el derecho a destruirla.

Mahatma Ghandi

ALEXANDER LÓPEZ-QUIROZ*

* Magister en Derecho Constitucional. Especialista en Derecho Público, Ambiental y Disciplinario, Colombia. alexanderlopezquiroz@yahoo.es

RECIBIDO: O7 DE OCTUBRE DE 2013. ENVÍo A PARES: 11 DE OCTUBRE DE 2013. APRobado Por PARES: 3 dE ENERO DE 2014. ACEPTAdo: 24 DE FEBRERO DE 2014.

DOI: $10.5294 / D I K A .2014 .23 .2 .3$

PARA CITAR ESTE ARTÍCULO / TO REFERENCE THIS ARTICLE / PARA CITAR ESTE ARTIGO 


\section{RESUMEN}

Según el artículo 3 la ley 99 de 1993, en Colombia se trata a las generaciones futuras (GF) como sujetos de derechos y obligaciones porque según la ley colombiana y la mayoría de tratados internacionales de carácter ambiental ratificados por el pais, las GF tienen el derecho de recibir de la generación presente "unos recursos naturales y un ambiente en tales condiciones que les permita satisfacer sus necesidades de vida”. Desde esta óptica, ¿son las generaciones futuras reconocidas por el derecho colombiano como sujetos de derechos y obligaciones? ¿Cuentan estas con personalidad jurídica? Este documento busca dar respuesta a estos interrogantes a partir de una revisión de los conceptos de persona y personalidad jurídica dentro del marco del Código Civil colombiano.

\section{PALABRAS CLAVE}

Persona, generaciones futuras, derechos, personalidad jurídica. 


\section{ABSTRACT}

According to Article 3 of Law 99/1993, future generations (FG) in Colombia are treated as persons with rights and obligations. This is because Colombian law and most international environmental treaties ratified by the country indicate future generations are entitled to inherit from the present generation "natural resources and an environment in conditions that allow them to satisfy the basic necessities of life". Viewed from this perspective, the issue is whether future generations are recognized in Colombian law as persons with rights and obligations? Do they have a legal personality? This paper attempts to answer those questions based on a review of the concepts of person and legal personality found in the framework of the Colombian Civil Code.

\section{KEYWORDS}

Person, future generations, rights, legal personality. 


\section{RESUMO}

Segundo o artigo $3^{\circ}$ da Lei 99 de 1993, na Colômbia, as gerações futuras (GF) são tratadas como sujeitos de direitos e obrigações porque, de acordo com a lei colombiana e a maioria de tratados internacionais de caráter ambiental ratificados pelo país, as GF têm direito a receber da geração presente "uns recursos naturais e um ambiente em tais condições que lhes permitam satisfazer suas necessidades de vida”. Sob esse ponto de vista, as GF são reconhecidas pelo direito colombiano como sujeitos de direitos e obrigações? Elas contam com personalidade jurídica? Este documento pretende dar resposta a esses questionamentos a partir de uma revisão dos conceitos de pessoa e personalidade jurídica no âmbito do Código Civil colombiano.

\section{PALAVRAS-CHAVE}

Pessoa, gerações futuras, direitos, personalidade jurídica. 
SUMARIO: INTRODUCCIÓN; 1. ¿GENERACIONES FUTURAS ACREEDORAS DE DERECHOS SEGÚN EL Código CIVIL COLOMBIANO?; 2. ¿QUÉ ES DERECHO?; 3. ¿QUIÉN ES PERSONA?; 4. SEgún EL DERECHO COLOMBIANO ¿QUE ES PERSONALIDAD JURÍDICA?; 5. ¿QUÉ SE ENTIENDE POR GENERACIONES FUTURAS (GF)?; 6. ¿EXISTEN OBLIGACIONES CON LAS GENERACIONES FUTURAS?; 7. ¿ES EXIGIBLE JURÍDICAMENTE LA OBLIGACIÓN CREADA EN EL ARTí́CULO 3 DE LA LEY 99 DE 1993?; 8. iSON LAS GF SUJETOS DEL DERECHO?; 9. ConClusiones; 10. Consideraciones Finales; 11. Propuestas; Bibliografía.

\section{INTRODUCCIÓN}

De acuerdo con la definición de desarrollo sostenible plasmada en la Ley 99 de 1993, se infiere que se consagra un aparente nuevo sujeto de derechos y obligaciones denominado generaciones futuras (GF), entendidas como beneficiarias de un ambiente sano y suficientes recursos naturales para satisfacer sus necesidades. Una breve revisión del concepto de GF permite vislumbrar que existen algunos vacíos en su aplicabilidad, como se describe a lo largo de este documento.

Se parte de que el derecho regula las relaciones entre personas sin importar su naturaleza, y de que las personas naturales adquieren dicha condición jurídica cuando han nacido vivas, $\mathrm{y}$, por tanto, las personas naturales adquieren la calidad de sujetos de derechos y obligaciones. Es entonces necesario realizar un breve recordatorio de algunas definiciones legales de persona, derecho y obligación, con el fin de esclarecer los alcances de estos conceptos.

Con esto no se pretende establecer una respuesta absoluta, sino un llamado para conversar sobre algunas definiciones legales aquí planteadas, y analizar si las GF son sujetos de derechos y obligaciones según lo establecido en el artículo 3 de la Ley 99 de 1993, en concordancia con el Código Civil.

El derecho internacional, en declaraciones y tratados, establece deberes de las generaciones presentes, para con las generaciones futuras, sin haber determinado de manera expresa o tácita su condición de seres humanos o personas y, como tales, sujetos de derechos, por ello se realiza el presente planteamiento desde el sistema jurídico colombiano.

\section{1. ¿LAS GENERACIONES FUTURAS SON ACREEDORAS DE DERECHOS SEGÚN EL CÓDIGO CIVIL COLOMBIANO?}

Con posterioridad a la Segunda Gran Guerra, se inicia la discusión acerca de las GF; ${ }^{1}$ pero es a partir de la declaración de Estocolmo (1972) que se emplea la expresión "Generaciones Futuras" para definir a aquellas personas que existirán en

1 Históricamente han existido importantes reflexiones sobre la importancia de la conservación del medioambiente para la preservación de la vida humana, incluso en la literatura. En 1928, aparece la obra literaria La Vorágine, en la que José Eustacio Rivera relata cómo con la tala indiscriminada de los árboles de caucho en la Amazonia colombiana se amenaza a las generaciones venideras. José Eustacio Rivera, La Vorágine, Bogotá, Editorial Momo, 1928, p. 186. 
el futuro y para las cuales se debe pensar y actuar en el presente. En la declaración de Estocolmo se hizo mención a las GF en dos proclamas: en el numeral 6, se indica que la defensa y el mejoramiento del medio humano para las generaciones presentes y futuras, debía convertirse en meta imperiosa de la humanidad. De igual forma, en el principio 2 se dice que “... los recursos naturales de la tierra [...] deben preservarse en beneficio de las generaciones presentes y futuras”.

Posteriormente, en 1987, en el Informe Bruntland (Nuestro futuro común), las GF aparecen al definir el desarrollo sostenible como aquel que satisface las necesidades de las generaciones presentes, sin comprometer la capacidad de las GF para satisfacer sus propias necesidades. Surge ahí la expresión que hoy genera cuestionamiento, en lo que se refiere a las generaciones venideras frente a la responsabilidad actual de conservación y protección del medioambiente en Colombia.

Más adelante, otras normas internacionales se refieren al tema, como la Resolución 44/228 de la Asamblea General del 22 diciembre de 1989, relativa a la Conferencia de las Naciones Unidas sobre el Medio Ambiente y el Desarrollo, además de las Resoluciones 43/53 del 6 diciembre de 1988, la 44/207 del 22 diciembre de 1989, la 45/212 del 21 diciembre de 1990, y la 46/169 del 19 diciembre de 1991; todas estas orientadas a la protección del clima mundial para las generaciones presentes y futuras.

Adicionalmente, en la Convención Marco de las Naciones Unidas sobre el Cambio Climático, ${ }^{2}$ ratificada por Colombia por la Ley 164 de 1994, se consagra en los considerandos que las naciones están “...decididas a proteger el sistema climático para las generaciones presentes y futuras”.

Finalmente, en la década de los noventa, con la Declaración de Río de Janeiro, conocida también como "Cumbre de la Tierra", se estableció en el principio 3 que "El derecho al desarrollo debe ejercerse en forma tal que responda equitativamente a las necesidades de desarrollo y ambientales de las generaciones presentes y futuras" (Declaración de Rio de Janeiro, 1992).

En este contexto, aparecen las GF como un nuevo sujeto del derecho internacional, creado por normas internacionales, sin conciliación previa con los marcos jurídicos específicos de cada país individual. Como se verá a continuación, en la legislación colombiana este nuevo "sujeto" no aparece articulado con el marco jurídico, ni en lo general, ni en lo referente a las personas como sujetos de derecho.

En Colombia, el concepto de GF es incorporado en la legislación nacional en la definición de desarrollo sostenible suscrita en el artículo 3, Ley 99 de 1993, en el cual el desarrollo sostenible se proclama como aquel que:

... conduzca al crecimiento económico, a la elevación de la calidad de la vida y al bienestar social, sin agotar la base de recursos naturales renovables en que se sus-

2 Realizada en Nueva York el 9 de mayo de 1992. 
tenta, ni deteriorar el medioambiente o el derecho de las generaciones futuras a utilizarlo para la satisfacción de sus propias necesidades.

A partir de esta definición, las GF fueron aceptadas e incorporadas en casi todos los escenarios sociales, académicos y políticos, sin haber dado un debate previo sobre los alcances del término como sujetos de derecho, y sin contemplar si realmente lo eran o no. Esto implicó una aceptación de las presuntas consecuencias jurídicas, sociales, económicas y ambientales del término, el cual fue aceptado de manera irreflexiva, ${ }^{3}$ casi inconscientemente, como si fuese un tema acabado. ${ }^{4}$

En la actualidad, el tema de las GF y sus consecuencias en los diferentes ámbitos no son tema de opinión o discusión. Por el contrario, el concepto es ampliamente aceptado como verdad sabida sin siquiera reflexionar acerca de ello.

Para determinar si las GF son sujetos de derecho o tienen personalidad jurídica, es necesario examinar algunos conceptos fundamentales del derecho, como son: derecho, persona y personalidad jurídica.

\section{2. ¿QUÉ ES DERECHO?}

El profesor Javier Hervada nos dice que los romanos definieron el arte del derecho como la ciencia de lo justo y de lo injusto, aclarando que decir lo justo es nombrar el derecho porque son lo mismo. De lo anterior se deriva que lo injusto es la lesión del derecho. "Lo suyo, lo de cada uno, este es el objeto del saber del jurista. A la cosa de cada uno - a lo suyo - le llamamos derecho, el derecho de cada cual; de donde determinar lo suyo, lo de cada uno, es determinar el derecho". ${ }^{5}$

Según los profesores Arturo Valencia Zea y Álvaro Ortiz Monsalve, la ciencia jurídica emplea la palabra "derecho" en dos sentidos principales: derecho objetivo y derecho subjetivo. El primero se define como el conjunto de normas que gobiernan la vida de los hombres que viven en sociedad, mientras que el segundo está referido a las facultades o los poderes de que son titulares las personas y que sirven para satisfacer sus necesidades. ${ }^{6}$

De lo anterior se concluye que el derecho regula las relaciones de las personas entre ellas, y, por tanto, es una forma de "reglamentación" de la conducta humana.

3 En el sentido de que acarrea unas consecuencias jurídicas que no se han discutido ni debatido, y, por tanto, no se ha modificado el marco jurídico vigente, para adaptarlo a las nuevas exigencias del concepto. Surge aquí la pregunta: ¿estamos ante unos nuevos sujetos de derechos y obligaciones? Si la respuesta es positiva, tenemos entonces que este nuevo sujeto no está regulado en el Código Civil colombiano.

4 Como lo expresa el profesor Amílcar Herrera: “... hemos sido conducidos a aceptar la lógica implícita del sistema, nunca expuesto explícitamente, sino introducido de manera sutil en nuestras mentes a través de una repetición inacabable de declaraciones cuyas premisas se dan por sentadas y que por lo tanto no están sujetas a discusión”. Amílcar Herrera, La larga jornada, la crisis nuclear y el destino biológico del hombre, México, Siglo XXI, 1981, p. 15.

5 Javier Hervada, ¿Qué es el derecho?, Bogotá, Editorial Temis, 2005, p. 10.

6 Arturo Valencia Zea y Álvaro Ortiz Monsalve, Derecho Civil, t. I, Bogotá, Temis, 14 ed., 2008. 
Si la norma jurídica solo puede recoger como contenido los hechos que pueden predicarse de una persona, entonces el derecho se ocupa solo de las "personas" que existen, ${ }^{7}$ pues la existencia como "persona" comienza al nacer, tal y como lo establece el Código Civil colombiano:

... si el nacimiento constituye un principio de existencia entrará el recién nacido en el goce de todos sus derechos como si hubiere existido al tiempo en que se le defirieron. En cambio, alli donde el concebido es "persona por nacer", adquiere sus derechos desde la concepción. Y si nace muerto, estos derechos se extinguen. ${ }^{8}$

Para el caso colombiano, las GF se legalizan a partir de la definición de desarrollo sostenible según el artículo 3 de la Ley 99 de 1993. Este derecho consiste en que se les dejen a las GF recursos naturales y un ambiente sano para la satisfacción de sus necesidades. Desde esta óptica, la norma establece en cabeza de las GF un "derecho".

Pero, según las reglas del Código Civil colombiano, ¿existe este beneficiario del derecho? En caso de que la respuesta sea afirmativa, se tiene definido que todo derecho conlleva una obligación.

Según lo anterior, ¿debemos establecer cuál es el limite de nuestra obligación? Para poder responder a esto es necesario examinar a profundidad los alcances del derecho civil, la regulación de la personalidad jurídica, las obligaciones y los requisitos, y la doctrina de la Corte Constitucional en el tema del derecho a la vida.

Para intentar dar respuesta a estos interrogantes es necesario leer de nuevo el contenido del artículo 3 de la Ley 99 de 1993, en el sentido de las consecuencias en el marco jurídico colombiano vigente, en especial en concordancia con el Código Civil. Esta norma se refiere al derecho de las GF a recibir unos recursos naturales renovables y un entorno sano, con el fin de satisfacer sus propias necesidades. En otras palabras, se entiende que las GF tienen el derecho legal a recibir de nosotros, la generación presente, recursos naturales renovables y un entorno con lo suficiente para garantizar la satisfacción de sus necesidades. Surge la pregunta: ¿cuánto será lo suficiente y cuáles serán sus necesidades?

De esta norma también se infiere que el crecimiento económico llevará a la elevación de la calidad de vida, según lo que los anglosajones han denominado desarrollo. En este contexto, el artículo 3 se entiende como la obtención de mejores viviendas, acceso a la educación y a la cultura, a una alimentación prolija, a los servicios públicos esenciales, a la salud y a la redistribución de la riqueza. En

$7 \quad$ En tanto se pueden relacionar con otros y lo hacen a través del Derecho y otras formas sociales y políticas.

8 A diferencia de Colombia, “... los códigos civiles de Argentina, Paraguay y Perú reconocen expresamente que el nasciturus es una 'persona por nacer' o 'sujeto de derecho', que puede desde la concepción, adquirir derechos y contraer obligaciones”. Verónica Pía Delgado Schneider, "El principio de la protección legal de la vida y la salud del nasciturus. Revista de Derecho Privado, 12-13 (2007), pp. 96-97. 
otros términos, a vivir en una democracia. ${ }^{9}$ De igual forma, se infiere un derecho subjetivo y una obligación. ${ }^{10}$

Pero se trata de establecer primero si las GF pueden o no acceder al derecho ambiental, y si este es un derecho real. ${ }^{11}$ Debe ser real ya que Colombia es un Estado social de derecho, que se caracteriza por la materialización de los derechos fundamentales, y la Corte Constitucional colombiana ha catalogado al medioambiente como un derecho fundamental por conexidad con la salud y la vida. ${ }^{12}$

Por lo anterior, para responder a estas inquietudes, se debe establecer primero quiénes son personas, o, lo que es lo mismo, quiénes son sujetos de derechos y obligaciones.

Según nuestro marco jurídico vigente, ${ }^{13}$ si las GF se componen solo de personas futuras, entonces no se podrán percibir, porque no existen. Por otro lado, en el caso de que las dichas generaciones se constituyan de personas futuras y presentes, entonces sí adquiririan personalidad juridica, por lo que tendrian derechos subjetivos o, por lo menos, parte de ellos.

Para poder clarificar esta propuesta es necesario ahondar en el concepto de persona.

\section{3. ¿QUIÉN ES PERSONA?}

El profesor Mario de la Cueva ${ }^{14}$ menciona:

En los debates históricos de todos los tiempos han estado constantemente presentes dos tendencias que podrían subsumirse en fórmulas; la doctrina de la persona como esencia y de su consecuente libertad entre el derecho y el Estado, y la tesis de la persona como una categoría jurídica.

... Cada uno de los integrantes de la humanidad es, en razón de su dignidad intrínseca, el fundamento y el fin del derecho, por que quien habla de un ser que por exigencia de propia naturaleza es titular de derechos, destinatario de deberes jurídicos, sujeto responsable y centro de una esfera jurídica que necesariamente le pertenece.

9 Democracia no significa elecciones, significa justicia social, igualdad material, oportunidades para el bienestar humano.

10 Todo derecho implica también un deber. Según la definición, la obligación se compone de tres elementos: acreedor, obligado y el objeto de la obligación. El deber es del obligado y el derecho de exigirla es del acreedor.

11 ¿Es posible cumplir este mandato? Una ley tiene que ser eficaz porque, de no serlo, no cumpliría ni su fin ni haria lo debido: regular. La eficacia de la ley no consiste en que necesariamente se cumpla, sino en que sea adecuada a la situación regulada y que pueda cumplirse. De ahí que no es eficaz una ley que sea, o inadecuada a la realidad regulada, o imposible de cumplir. La eficacia de la ley no es lo mismo que la observancia plena de la misma a partir del cumplimiento inexorable de los destinatarios. Corte Constitucional, sentencia C-542 de 1993, M. P. Vladimiro Naranjo Mesa.

12 Este tema puede ampliarse en las sentencias T-528 y T-415 de 1992, T-231 de 1993, T-550 de 2000.

13 Código Civil colombiano, Bogotá, Legis, 22 ed., 2009.

14 Ibid., p. 51. 
En otros términos, toda persona jurídica es sujeto de derechos, esto es, titular de cosas suyas que por otros son algo debido. Toda persona desde el momento mismo de su aparición en el mundo, tiene una dimensión jurídica, una juridicidad por la cual sustenta sus atributos y títulos que le son propios (CC, art. 74).

Los profesores Valencia Zea y Ortiz Monsalve explican:

Entiéndase por sujeto de derecho o persona el ente que tiene la capacidad para ser sujeto de las normas jurídicas (activa o pasivamente). [...] bien puede definirse el sujeto de derecho o persona como la capacidad atribuida por el ordenamiento jurídico a ciertos seres, para ser sujetos de hechos y consecuencias jurídicos. ${ }^{15}$

De las definiciones de estos profesores, que son las autoridades en el tema, se colige que persona es sinónimo de sujeto de derecho y, por tanto, persona es quien tiene capacidad para actos jurídicos.

Según el Código Civil colombiano, quienes son portadores de derechos y obligaciones son las personas (CC, arts. 73 y 74). Existen dos tipos de personas: naturales y jurídicas; las primeras las define el Código Civil en el artículo 73 así: "Las personas son naturales o jurídicas”. En este trabajo no nos ocuparemos de las personas jurídicas. Según el mismo código, en el artículo 74 se define como persona natural "...todos los individuos de la especie humana, cualquiera que sea su edad, sexo, estirpe o condición”. Se infiere de esta definición que persona es un ser abstracto, propio para el derecho; porque ontológicamente, el hombre no es posible sin esas condiciones naturales y sociales.

Según la definición anterior, son personas todos los individuos que pertenecen a la especie humana, entendiendo por especie la posibilidad de fecundación, es decir, pertenecen a una especie todos los seres que son capaces de procrear entre sí.

Si personas son todos los seres pertenecientes a la especie humana, es decir, los pasados, los presentes y los futuros, y si aceptamos que esta definición de persona no es temporal en lo que se refiere a quienes son personas, se puede concluir que: personas son todos los individuos humanos, sin importar su tiempo de existencia.

\section{SEGÚN EL DERECHO COLOMBIANO ¿QUÉ ES PERSONALIDAD JURÍDICA?}

Según la definición de persona del artículo 74 del Código Civil colombiano, y si se tiene en consideración que en el artículo 90 se establece que la existencia legal de toda persona principia al nacer — esto es, al separarse completamente de la madre-, es decir, se es persona al nacer, ${ }^{16}$ y este hecho jurídico tiene una

15 Arturo Valencia Zea y Álvaro Ortiz Monsalve, Derecho Civil, op. cit.

16 Verónica Pía Delgado Schneider, "El principio de la protección legal de la vida y la salud del nasciturus", op. cit. 
condición adicional para dicho reconocimiento, la de nacer vivo, ${ }^{17}$ por tanto, no se reconoce como persona o no tiene el reconocimiento legal de persona, el que no ha nacido.

$\mathrm{Al}$ respecto, la Corte Constitucional ha dicho lo siguiente:

La Constitución de 1991, constitucionalizó el concepto de personalidad jurídica al reconocer la primacía de los derechos inalienables de todo ser humano, al reconocer su personalidad jurídica, al garantizarle el libre ejercicio de su derecho de asociación, al reconocerle la facultad de adquirir derechos y obligaciones, al facultarlo para ejercitar sus derechos. Pues bien, el reconocimiento de la personalidad jurídica en la Constitución implica para el Estado colombiano el otorgamiento de dicha personalidad a todo ser humano por el solo hecho del nacimiento, la cual se extinguirá con su muerte. ${ }^{18}$

Por el hecho de ser persona, se entiende que goza de una personalidad jurídica, la cual no es otra cosa que la aptitud natural de todo individuo de la especie humana para ser sujeto activo y pasivo de relaciones pertenecientes a la esfera jurídica.

Todo hombre, por el solo hecho de serlo, independientemente de cualquier circunstancia o calidad individual, tiene por su condición ontológica de persona, una subjetividad jurídica, cuya atribución es obra de la misma naturaleza y del ordenamiento jurídico positivo. ${ }^{19}$

Se concluye, con base en lo anterior, que la personalidad jurídica es la base para que el hombre se relacione con otros en la sociedad o con el Estado, en otras palabras, es lo que permite las relaciones sociales del hombre en un Estado.

Pero la legislación colombiana ha amparado al que está por nacer, el nasciturus, ${ }^{20}$ y los artículos 91 y 93 del Código Civil se refieren al que está por nacer, o a los derechos del no nacido, garantizando su derecho a la vida, como ser vivo y ser humano en potencia. ${ }^{21}$

En Colombia, el Código Civil y, de igual forma, el Código Penal, regulan algunas relaciones jurídicas para con el nasciturus, en aras de garantizar su derecho a la vida. Es decir, se le adjudican derechos sin haber sido reconocido como sujeto de derecho y sin tener aún personería jurídica. Respecto del Nasciturus, la

17 “...ya que únicamente los 'nacidos vivos' gozan de personalidad jurídica”; Arturo Valencia Zea y Álvaro Ortiz Monsalve, Derecho Civil, t. I, Bogotá, Temis, 14 ed., 2008, p. 348.

18 Corte Constitucional, sentencia C-355 de 2006, salvamento de voto Jaime Araújo Rentería.

19 Arturo Valencia Zea y Álvaro Ortiz Monsalve, Derecho Civil, op. cit.

20 El concebido que no ha nacido, es decir, se encuentra en el vientre materno.

21 Los códigos civiles de Chile, Ecuador, El Salvador, Honduras, Nicaragua y Panamá, consagran de manera expresa el principio de la protección legal de la vida y la salud del que está por nacer. Verónica Pía Delgado Schneider, "El principio de la protección legal de la vida y la salud del nasciturus", op. cit., p. 99. Contrario a Colombia, los códigos civiles de Argentina, Paraguay y Perú reconocen expresamente que el nasciturus es una "persona por nacer" o "sujeto de derecho", que puede, desde la concepción, adquirir derechos y contraer obligaciones; ibid., pp. 96-97. 
Corte Constitucional ha establecido que no se trata de una cosa, sino de un ser humano en potencia y, como tal, se trata de "vida" y tiene derecho a ella. De acuerdo con esto, para garantizarle derechos a la persona no se requiere que nazca con vida. ${ }^{22}$

La Corte Constitucional establece que el nasciturus tiene derecho a la vida desde la concepción por tratarse de "una vida humana" en potencia. En otras palabras la Corte, en la interpretación de la norma, no le da al nasciturus la calidad de sujeto de derechos y obligaciones, pues esta disposición está orientada a proteger la vida, entendiendo proteger como la actividad estatal de conservarla, hecho que no trasciende al mundo social o a las relaciones jurídicas.

En la sentencia C-355 de 2006, en relación con el aborto, la Corte Constitucional establece que el derecho a la vida se protege desde la concepción, sin que dicha afirmación implique un reconocimiento del nasciturus como persona o sujeto de derechos y obligaciones. Según la aclaración de voto del magistrado Jaime Araújo Rentería, “... el nasciturus es ser protegido por el derecho pero claramente no tiene personalidad jurídica; y no la tiene por cuanto no puede adquirir bienes o servicios, contratar, pagar impuestos, etc."

De esta sentencia se colige que, solo al nacer se es sujeto de derechos y obligaciones, o, lo que es lo mismo, solo al nacer se adquiere personalidad jurídica, lo que significa que solo se puede acceder a derechos subjetivos cuando suceda el hecho y la condición legal de nacer vivo.

Este derecho se ratifica en el artículo 93 del Código Civil colombiano, donde se aclara que:

... los derechos que se diferirian a la criatura que está en el vientre materno, si hubiese nacido y viviese, estarán suspensos hasta que el nacimiento se efectúe. Y si el nacimiento constituye un principio de existencia, entrará el recién nacido en el goce de dichos derechos, como si hubiese existido al tiempo en que se defirieron.

Esta norma se refiere al nacimiento biológico y, al mismo tiempo, al nacimiento de la personalidad del ser humano, desde la perspectiva de la opción de gozar de derechos patrimoniales y de otras estirpes, los cuales únicamente se adjudican en cabeza de este nuevo ser humano, cuando se cumple la condición de nacer vivo.

En el caso que no se cumpla con la condición de nacer vivo, exigida en el inciso primero del artículo 90, estos derechos pasarán a otras personas como si la criatura no hubiese jamás existido.

Se confirma lo manifestado en el salvamento de voto del magistrado Jaime Araújo Rentería, en la sentencia C-355 de 2006, según la cual se protege la vida no por

22 Corte constitucional, sentencia C-013 de 1997, M. P. José Gregorio Hernández Galindo. 
tratarse de un sujeto de derechos y obligaciones, sino por el hecho de que la ley protege al nasciturus. ${ }^{23}$

Recapitulando los conceptos examinados hasta aquí, se tiene que: son las personas naturales nacidas vivas las que gozan de personalidad jurídica, $y$, por tanto, solo las personas naturales nacidas vivas son sujetos de derechos y obligaciones, mientras que las que están por nacer y los no concebidos, no son sujetos de derecho.

Para la primera categoría de personas los derechos subjetivos de toda índole son plenos, mientras que la segunda categoría solo goza del derecho a la vida y adquirirán los demás derechos siempre y cuando se cumpla la condición de nacer vivas.

Frente a los no concebidos aún no se ha dicho nada en esta legislación ${ }^{24}$. Los no concebidos se incorporan a la legislación colombiana a partir de la definición de persona, la cual se refiere a la especie humana.

Este hecho sugiere la ampliación del concepto de "sujeto de derechos y obligaciones" o personalidad jurídica, la cual debería ser reconocida a todos los miembros de la especie humana, como especie, ello implica reconocer el pasado y el futuro.

Solo de esta forma los miembros de las GF podrian ser sujetos de derechos desde el presente, pero esto es algo que aún no sucede en Colombia, según el marco legal vigente.

\section{5. ¿QUÉ SE ENTIENDE POR GENERACIONES FUTURAS (GF)?}

La palabra "generación" se deriva del latín conceptus, us o concepción, que según el Diccionario Español Latín Proyecto Palladium, se refiere a la procreación o permanencia de la especie como tal. La generación es la garantía de que la especie va a perdurar en el tiempo mientras las condiciones del entorno lo permitan. ${ }^{25}$

Según la definición del Diccionario de uso del español, ${ }^{26}$ se entiende por generación:

1. Acción de generar.

2. Acción de engendrar (procrear). *Reproducción.

23 Según se estipula en el delito de aborto, Código Penal.

24 El derecho colombiano regula relaciones entre personas, por ende, trata hasta ahora de personas presentes, reales.

25 Según Guillermo Foladori, no se puede separar la especie de su entorno pues existe interdependencia entre ellos: “...el fenotipo, a través de su grado de libertad de acción, modifica el medioambiente. El nuevo ambiente vuelve a seleccionar organismos (genes), que a su vez modifican nuevamente el ambiente"; Guillermo Foladori, "El comportamiento humano a la luz de las teorías biológicas de la evolución”, Revista Ludus Vitalis, VIII (14) (2000), p.169.

26 María Moliner, Diccionario de uso español, Buenos Aires, Del Nuevo Extremo S.A., 2007, p. 1447. 
3. Circunstancia de proceder de cierta persona en línea recta de descendientes. *Descendencia.

4. Conjunto de las personas que tienen aproximadamente la misma edad: los de mi generación. Frecuentemente, se designa con el nombre de un momento o de un acontecimiento con el que esa generación o su llegada a la mayor edad coincide o tiene especial relación.

De acuerdo con esta definición, si por generación se entienden todos aquellos que tenemos la misma edad, significa igualmente que vivimos en la misma época y recibimos la misma educación, entonces las GF son las personas que no cumplen con dicha condición. Se infiere, entonces, que nuestros hijos son un componente de las GF, así como los nasciturus y, por tanto, las GF se componen no solo de los no concebidos y de los por concebir, sino también de la personas presentes, que son sujetos de derechos.

Se puede decir entonces que por generaciones futuras no solamente deben entenderse aquellos seres humanos en potencia o futuras generaciones, sino también los seres humanos ya nacidos.

En la legislación colombiana encontramos que las GF se componen de tres tipos de persona: los nacidos, los nasciturus o que están en el vientre materno, y los por "concebir". ${ }^{27}$

Según el Código Civil colombiano, se puede afirmar que los primeros son sujetos plenos de derechos, mientras que los segundos y terceros tienen expectativa de adquirirlos. Es decir, los por "concebir" no son sujetos de derechos, puesto que se adquiere personalidad jurídica solo hasta el momento del nacimiento y se debe adicionar la condición de nacer vivo (CC, art. 90).

Es este el marco fáctico que soporta la estructura jurídica que regula legalmente el tema de la personalidad jurídica de las personas: nacer vivo para hacer uso de sus derechos.

Frente a los por "concebir", estos no existen en el derecho colombiano y tampoco en los tratados internacionales ratificados por Colombia.

Esta situación jurídica crea una aporia, al constituir legalmente un derecho, sin establecer previamente la condición de sujeto de derecho al acreedor del derecho creado. Cabe entonces preguntarnos, bajo el actual marco jurídico colombiano, ¿será este un derecho inexigible?

27 Artículo 90 CC. Se infiere de esta norma, en concordancia con la definición de GF, que es posible y probable que se presenten los por concebir. Concepto que ayuda a determinar quiénes de las GF son sujetos de derechos y obligaciones y quiénes no. 
Si las GF se constituyen de los nacidos, de los nasciturus y los por concebir, estos dos últimos, como se dijo, no serían sujetos de derechos, toda vez que no han nacido, y por tal no son sujetos de derechos y obligaciones. Pero son parte de la especie humana, y por definición legal deberían ser personas.

Lo anterior no impide que los nasciturus gocen de protección legal sobre la vida, además de adquirir derechos una vez hayan nacido. Los por "concebir" se quedan sin regulación legal alguna, excepto su pertenencia a la especie humana.

Si el legislador define a la persona como todo miembro de la especie humana, realiza una generalización extemporánea — sin consideración al tiempo-. Por tal razón, deben ser considerados y tratados como tal todos los miembros de la especie humana. Por tanto, si nuestros descendientes pertenecen a la especie humana, ellos son personas.

Al ser personas del futuro, de acuerdo con el artículo 3 de la Ley 99 de 1993, estamos obligados a respetar el derecho a la vida de todas esas personas del futuro. ${ }^{28}$ De esta forma los nacidos, es decir, las personas que se encuentran en el presente, tienen esa doble connotación, que es "ser parte del futuro desde el presente".

De conformidad con estos planteamientos, las GF que deben nacer, por ejemplo, en el 2025, no son catalogadas como sujetos de derecho, ergo no pueden acceder a ningún tipo de relación jurídica interpersonal y mucho menos a ser sujetos de derechos y obligaciones, ya que contradicen la definición de persona, la cual abarca a la especie humana de forma intemporal, que como todos los demás animales está programada genéticamente para permanecer en el tiempo.

Lo anterior acarrea una contradicción, puesto que la personalidad jurídica es la ficción jurídica que establece esa condición de aptitud o hace aptas para la vida jurídica a las personas, y si son personas todos los miembros de la especie humana, por ende, todos sus miembros deberían ser aptos para las relaciones jurídicas.

Nos preguntamos ¿cómo puede un ser humano, ser apto para las relaciones jurídicas si no ha nacido? El derecho, como creación especulativa del hombre, ${ }^{29}$ permite concretar derechos en las personas, y si el derecho busca lo justo, debe garantizar las condiciones necesarias para así poder lograr materializar el derecho a la vida de los miembros de la especie humana del futuro.

Y si la existencia de un entorno sano es garantía para una vida sana, es deber como especie garantizar el bienestar del entorno natural y social.

Y si el derecho no ha perdido su original finalidad, la justicia debería reconocer y otorgar a los miembros de las GF, las opciones jurídicas necesarias para exigir la

28 El artículo 3 de la Ley 99 de 1993, establece que: "El derecho al desarrollo debe ejercerse en forma tal que responda equitativamente a las necesidades de desarrollo y ambientales de las generaciones presentes y futuras".

29 Como una realidad que existe pero de forma intangible. 
protección del entorno natural y social, que permita y garantice esa existencia futura de la especie.

Podemos concluir, entonces, que la ley colombiana no responde con claridad frente a la necesidad de regular la personalidad jurídica según lo dispuesto en el artículo 3 de la Ley 99 de 1993, en tanto que por definición son personas los miembros de la especie humana y esto conlleva que se reconozca personería jurídica a las generaciones futuras.

\section{6. ¿EXISTEN OBLIGACIONES CON LAS GENERACIONES FUTURAS?}

Para analizar si la generación presente tiene obligación con las generaciones futuras es oportuno examinar el concepto jurídico de "obligación", ${ }^{30}$ estableciendo los requisitos, las características y las exigencias frente al objeto y sujetos de la relación.

Siguiendo al maestro Fernando Hinestrosa, la “obligación es la relación jurídica entre dos sujetos de derecho, con características propias en cuanto a ellos, al objeto sobre el cual recae, a su contenido, a la función social que cumple, a sus orígenes, razón de ser y manera de constituirse, desenvolverse y terminar". ${ }^{31}$

La obligación implica, por regla general, una participación dual. En palabras de Hinestrosa "poder-deber". ${ }^{32}$ En otros términos, en todo vínculo regulado por el derecho se presentan dos personas, el propietario o poseedor del derecho y el obligado frente a ese derecho. Este vínculo entre ellos debe referirse a algo externo, es decir un tercer elemento, el "objeto" de esa relación, que siempre ha de ser una conducta humana de acción o de omisión. ${ }^{33}$

Las obligaciones se presentan entre iguales, esto es, entre personas. En dicha relación poder-deber, el primero puede exigir del obligado una conducta determinada, que se abstenga o entregue algo, que haga, que le dé una prestación. El segundo, debe respetar el derecho del primero, y lo hace cumpliendo con la obligación acordada o con el cumplimiento de la ley, según sea el origen de la obligación.

Tenemos entonces que, según la definición, para la materialización de las obligaciones se requiere de dos personas o sujetos de derechos y obligaciones. De esta forma, como los segundos miembros de las GF, los nasciturus y los por concebir no son personas, no pueden ser los poseedores del derecho objetivo creado por el artículo 3 de la Ley 99 de 1993.

30 De acuerdo al Código Civil, las obligaciones nacen del acuerdo de voluntades de dos o más personas, de un hecho voluntario de la persona que se obliga, por los cuasicontratos, como consecuencia de un hecho que haya inferido daño a otra persona o por disposición de la ley.

31 Fernando Hinestrosa, Teoría de las obligaciones, concepto, estructura, vicisitudes, Bogotá, Editorial Universidad Externado de Colombia, 2002.

32 Idem.

33 Este vínculo u objeto es lo que la doctrina denomina: la prestación de dar o entregar un cuerpo cierto, realizar una actividad, omitir determinados actos, alcanzar un resultado. 
Frente al objeto de la obligación, la doctrina ha establecido las siguientes características: existir, ser posible (física o naturalmente), ser licito, estar determinado o ser determinable, ser de naturaleza patrimonial o, por lo menos, apreciable en dinero.

Al tenor del artículo 3 de la Ley 99 de 1993, el derecho al desarrollo debe ejercerse en forma tal que responda equitativamente a las necesidades de desarrollo y ambientales de las generaciones presentes y futuras. De esta manera, el objeto de la obligación será el del uso sostenible de los recursos naturales y dejar un ambiente apto para la vida. En este caso, los requisitos de licitud y existencia se cumplen.

Frente a que sea determinado o determinable, lo que el obligado debe saber es qué es lo que debe y cómo lo debe, lo mismo que el acreedor ha de saber qué es lo que puede esperar. Este principio se cumple si el objeto se ha determinado de manera suficiente. En otro caso, si la obligación se refiere a especie o género, se debe expresar su cantidad, la cual se señalará en unidades de medida acordes a su naturaleza.

La presunta obligación plasmada en la definición del desarrollo sostenible trata de dejar unos recursos naturales renovables suficientes para satisfacer las necesidades de las GF. Cabe cuestionarnos ¿a cuál generación futura nos referimos? ¿Nos referimos a la generación siguiente, o a la que le sigue, o a todas?

Si se trata de todas ellas, o de cualquiera de ellas, ¿cómo podemos determinar cuál es el requisito? ¿Cómo podemos determinar cuánta agua debemos conservar, apta para el consumo de las GF, o cuántos bosques conservar y suelos con adecuada cobertura boscosa? Esta sería la fecha incalculable.

La medición de la naturaleza futura necesaria es incalculable, pues se desconoce si los niveles de consumo actual se mantendrán, disminuirán o aumentarán en el futuro. Peor aún, si se persiste en la idea del desarrollo desde la concepción anglosajona del término, de crecimiento económico sin límites, la cuantificación de la obligación se hace inestimable.

Como no se tiene certeza acerca de los hábitos de consumo futuros y tampoco de las necesidades, entonces la obligación no esta determinada, ni es determinable según el texto del artículo 3, Ley 99 de 1993.

En tanto no conozcamos los factores que influyen en la determinación de la obligación de manera cuantitativa, como son los niveles de consumo de la sociedad futura y el volumen demográfico, ${ }^{34}$ no se puede medir la necesidad futura. Al no poder determinarse con la certeza exigida en la definición de obligación, no estamos ante una.

34 Se ha calculado científicamente que de seguir el nivel de procreación actual, nuestra población superará con creces el número de habitantes humanos de la actualidad. Algunos autores afirman que para el año 2015 la población humana se habrá incrementado en mil millones más y para el 2050 seremos nueve o diez mil millones de personas. Giovanni Sartori y Gianni Mazzoleni, La Tierra explota, superpoblación y desarrollo, Madrid, Taurus, trad. de Miguel Ángel Ruiz de Azúa, 2003. 
Por otro lado, se trata de una obligación de hacer, de realizar una acción, que consiste en usar los recursos naturales a un ritmo que logren las metas de desarrollo actuales, pero hacerlo de tal manera que alcance para la satisfacción de las necesidades de las GF.

Frente a esta acción, es aplicable lo que se esgrimió para la determinación de la obligación.

En conclusión la norma objetiva no cumple con los requisitos de la obligación. ${ }^{35}$ Como no los cumple, se concluye que no se trata entonces de una obligación, es decir, esta no existe, y al no existir no es exigible, por ende, no hay derecho en cabeza de las GF, ni obligación de las generaciones presentes.

\section{¿Qué y cuáles son las obligaciones para con las generaciones futuras?}

Supongamos que la obligación se pudiera determinar. Como las GF, conformadas por los seres nacidos, los nasciturus y los por concebir, tienen derecho a los recursos naturales renovables suficientes y al medioambiente sano que pueda satisfacer sus necesidades, y nuestros hijos (vivos en el presente) hacen parte de los nacidos y al mismo tiempo de las GF, entonces nuestros hijos, bajo la doble connotación de estar presentes pero como miembros de las GF, son acreedores de esta obligación, pero a la vez son consumidores de los recursos naturales renovables.

De lo anterior se desprende que los seres nacidos son al mismo tiempo acreedores y obligados, por ende, se tipifica la figura jurídica de la confusión por parte de esa generación que subsiste con la nuestra, frente a la obligación legal sobre los recursos naturales renovables y el medioambiente sano. Al constituirse la figura de la confusión en ellos, entonces desaparece la obligación y el derecho frente a ellos mismos. Por otro lado, si aceptamos que a pesar de no cumplir los requisitos de las obligaciones las aceptamos como una obligación natural ${ }^{36}$ o semejante, entonces nos queda la obligación frente a ellos, no exigible ante los tribunales.

A pesar de lo anterior, también se puede colegir que la obligación de nuestra generación es doble respecto de los hijos. Primero debemos conservar y proteger los recursos naturales renovables. Segundo, debemos brindarles una educación ecológica basada en un concepto del mundo como sistema, como unidad; brindarles una educación holística para que desde el presente asuman el destino de su propio futuro, que es de lo que trata el mandato comentado.

También, como parte esencial de la educación, impartir una educación política y con ella inducir la necesaria participación activa en las decisiones ambientales, que se constituyen en decisiones de supervivencia de nuestra especie.

35 Que sea cierta, determinable o determinada, que sea físicamente posible, entre otras.

36 "Artículo 1527. Las obligaciones son civiles o meramente naturales. Civiles son aquellas que dan derecho para exigir su cumplimiento. Naturales las que no confieren derecho para exigir su cumplimiento, pero que cumplidas autorizan para retener lo que se ha dado o pagado, en razón de ellas”. 
Estas obligaciones implican cambios de paradigmas, esquemas mentales y económicos establecidos desde la Ilustración, el sistema capitalista y la Revolución Industrial. Un cambio de paradigma como el planteado requerirá de insignes esfuerzos económicos y mentales para superar el concepto de la Tierra como objeto de apropiación y de recursos naturales como fuente de producción e ingresos.

De igual manera, tenemos la obligación de generar políticas de planificación y establecer controles de crecimiento demográfico y manejo del entorno, con el fin de que el futuro de las GF sea cierto y no improbable, por causa de la acción alienante del desarrollismo, impuesto en aras de alcanzar niveles de comodidad y consumo anglosajones.

\section{7. ¿ES EXIGIBLE JURÍDICAMENTE LA OBLIGACIÓN CREADA EN EL ARTÍ́CULO 3 DE LA LEY 99 DE 1993?}

Según el Código Civil, y al igual que en los contratos, las obligaciones nacen del acuerdo de voluntades. Es un hecho voluntario de la persona que se obliga, como sucede en la aceptación de una herencia y en los cuasicontratos, o como consecuencia de un hecho que ha inferido injuria o daño a otra persona, o como en los delitos por disposición de la ley.

En el caso de estudio, el derecho y la obligación frente a las GF surge de un mandato legal, consagrado en la Ley 99 de 1993. De igual manera, el artículo 488 del Código de Procedimiento Civil dice que las obligaciones se pueden exigir, siempre y cuando sean claras, expresas y actualmente exigibles.

Al revisar estos requisitos de la obligación, tenemos que para el caso que tratamos existe claridad en la misma, pues expresa claramente que debemos proteger y conservar los recursos naturales y un entorno sano. En cuanto a que el requisito sea expreso (la obligación debe estar determinada o cuantificada) no se cumple, como quedó demostrado anteriormente. En este caso, como consecuencia de la ausencia de este requisito, la obligación se torna inexigible.

Adicionalmente, si aceptamos como cierto lo manifestado en el documento del club de Roma, "Límites al crecimiento", ${ }^{37}$ cabe cuestionarnos ¿cómo sabremos qué y cuánto es lo necesario para la existencia de las GF, como seres humanos merecedores de una existencia digna?

Si tomamos como existencia digna el concepto de calidad de vida que se ostenta, y considerando el nivel de consumo actual de las sociedades occidentales, entonces el planeta entero no bastará para esa existencia. Podemos concluir que al

37 En el que se afirma que el planeta es limitado, y, por ende, los niveles de producción y consumo de nuestras sociedades ponen en peligro la permanencia de los denominados recursos naturales renovables, y con ello la existencia de la especie humana y demás especies vivas. 
ritmo de consumo y crecimiento demográfico actual, esta obligación es físicamente imposible de cumplir, ${ }^{38}$ lo que nos confirma que esta obligación es inexistente.

Por lo anterior, la obligación para con las GF es una expectativa mas no un derecho, en tanto que, como lo legisló el Congreso de la República de Colombia, no quedó claramente descrita la obligación consagrada en la Ley 99 de 1993, o por lo menos los límites de esta. No es posible establecer el cuánto, el cómo y el dónde de la obligación.

Tal y como se muestra en la ley, el Congreso transcribió un principio ambiental internacional que, dentro del marco jurídico colombiano, se encuentra vacío de eficacia y efectividad por no poderse reclamar.

Al mismo tiempo, dicho principio carece del sujeto dueño o acreedor del derecho, por no contar con personalidad jurídica o ser apto para relaciones jurídicas, esto aunado a su imposibilidad física de cumplimiento.

De acuerdo al Código Civil, cuando una obligación no se puede exigir judicialmente, se la llama obligación natural. Dentro de la definición de estas no se contemplan las creadas por la ley, por ende, y bajo el principio de legalidad y al no tratarse de una relación mercantil (entre los obligados a la conservación del entorno y dejarles recursos naturales para la existencia de las GF), no se puede asumir la costumbre como hecho creador de derechos entre las partes, como sí sucede en el derecho mercantil.

Adicionalmente, la Ley 99 de 1993 no estableció ni condición ni plazo para el cumplimiento de la obligación, por ende, no se sabe a partir de cuándo es su exigibilidad. Es decir que la obligación legal creada no es exigible, por no establecer el cuándo o el por qué del cumplimiento de la obligación. Se puede argüir que la obligación se hizo exigible a partir de la publicación de la Ley 99 de 1993, supuesto que sería válido desde la óptica de una interpretación abierta, extensa, no literal de la norma.

Si tomamos la fecha de promulgación de la ley (diciembre 22 de 1993) como aquella a partir de la cual la obligación es exigible, entonces estaríamos ante un incumplimiento del mandato legal según las predicciones y los cálculos del Instituto de Hidrologia, Meteorología y Estudios Ambientales (IDEAM) para el año 2025, frente al tema de acceso al agua en las cabeceras municipales del país. ${ }^{39}$

Aceptando a título de discusión que la obligación existe, su incumplimiento acarrearía una consecuencia jurídica. Entonces, en el caso de que nosotros no logre-

38 Dijo Rousseau: "Todo sale perfecto de manos del autor de la naturaleza; en las del hombre todo degenera. A esta tierra la fuerza a que dé las producciones de otra", alli se resume lo que acontece con el uso que damos a nuestro planeta, el cual probablemente continúe bajo las premisas aceptadas como verdad hoy: desarrollo, consumo, crecimiento, desarrollo sostenible; Juan Jacobo Rousseau, Emilio o de la educación, México Porrúa, 13 ed., 1999.

39 Periódico El Tiempo, Bogotá, 2008. 
mos preservar los suficientes recursos naturales renovables, ¿estaremos atentando contra la vida de las GF? ¿Debemos ser juzgados por tentativa de homicidio, como lo plantea Valencia Iragorri ${ }^{40}$, desde mi punto de vista sería tentativa de genocidio. ¿Cuándo debemos realizar la conducta típica? ${ }^{41}$ ¿Hoy, mañana, o cuándo las GF se enfrenten a la escasez y a no tener los recursos naturales renovables suficientes para su existencia?

La contaminación ambiental por fuera de los marcos permitidos acarrea unas sanciones administrativas, generalmente pecuniarias.

Frente a estas conductas tipificadas, las sanciones penales aplicadas en Colombia no compensan los daños ambientales generados, a pesar de ser estos evidentes; este es el caso de la pérdida del río Bogotá y la deforestación de las cordilleras, entre otros. Sobre el incumplimiento de esta obligación, no se conoce hasta la fecha que se haya adelantado proceso penal alguno, con ocasión de estos "ecocidios".

Hoy dia se sabe y se acepta, por lo menos legalmente, que un entorno sano es un requisito para garantizar la vida en la Tierra. Ante este hecho, la contaminación ambiental y otros deberían catalogarse como tentativas de genocidio, ya que se atenta contra la supervivencia de la especie humana. ${ }^{42}$

De aquí podemos concluir que ante el vacío legal al respecto, no existe sanción legal por el incumplimiento de la presunta obligación con las GF.

\section{8. ¿SON LAS GENERACIONES FUTURAS SUJETOS DEL DERECHO?}

Todo derecho objetivo requiere de un sujeto para materializarse y hacerse real. Cabe entonces preguntarnos, si en las condiciones actuales del marco legal colombiano, las GF pueden exigir el cumplimiento de la obligación legal referida.

Si los derechos se plasman en seres humanos nacidos vivos, y como por definición, una parte de las GF no han nacido y los otros están por ser concebidos, la ley colombiana no les concede el derecho de exigir la titularidad de aquel derecho. Como se explicó, los no nacidos y los que están por ser concebidos no se encuentran enmarcados ni reconocidos por la ley colombiana, y no tienen capacidad de adquirir derechos subjetivos. Por ende, el sujeto de derecho de la obligación legal se refiere solo y exclusivamente a los ya nacidos.

Si aceptamos que los niños, púberes y los adultos jóvenes hacen parte de las GF y pueden representarlas hoy, en el presente debemos permitir que ellos participen

$40 \mathrm{Si}$ el entorno es necesario para la vida, en especial la humana, entonces su afectación es un atentado contra la vida y la vida humana. De lo que se concluye que la vida se debería tener como bien jurídico tutelado por las normas penales ambientales.

41 Se entiende como el cumplimiento de la descripción legal. Se usa más en las normas de carácter sancionador sin ser exclusivo este principio de esta área del derecho. María Alejandra Valencia Iragorri, El delito ecológico en el derecho penal colombiano, Bogotá, Ediciones Forum, 1995.

42 Recordemos que la Tierra es un sistema integral y, por ende, cualquier daño o alteración en sus procesos intrínsecos afectará al resto del sistema. 
en las decisiones que afectan el ambiente, la cultura y la educación, puesto que las decisiones que hoy tomamos afectan de manera directa su futuro y el futuro mismo de la permanencia de la vida como la conocemos.

Es imperante aceptar que ellos son las GF de nuestra especie, y que podremos afectar de manera negativa su calidad de vida, por el deterioro del ambiente, por el excesivo consumo, por la mala disposición de los residuos sólidos, entre otros.

Si las GF están constituidas por los niños presentes, y considerando el artículo 44 de la Constitución Política, ellos gozan del privilegio de que sus derechos primen sobre los derechos de los demás, entonces estamos obligados desde hoy a realizar todo lo necesario para garantizar su derecho a la existencia, cumpliendo con la conservación y protección de su medioambiente, y creando mecanismos de participación para ellos en torno a las decisiones ambientales que afectan su presente y su futuro.

Las decisiones que llegaren a tomar los niños y jóvenes tendrían mayor valor vinculante que las de la generación presente, tal como se infiere de la ley de la infancia. Pero el tema se ha planteado de forma tangencial y las entidades responsables no le han dado la trascendencia que conlleva dicha norma para el presente y futuro de la vida.

La idea que más me gusta de este texto es el hecho de plantearlo como responsabilidad de las generaciones actuales, y no como derecho de las futuras, ya que algunos de los problemas jurídicos se refieren a la dificultad de establecer un derecho para alguien que no está presente, o la necesidad de buscarles una representación a través de una institución. Alcolea dice preferir manejarlo como un deber actual, mas no como derecho; de forma tácita hace notar que las GF no tienen derecho, por no existir, ya que el derecho es de los vivos.

De otro lado, a nivel internacional, como la "Declaración sobre las responsabilidades de las generaciones actuales para con las generaciones futuras”, Unesco 1997, y los demás documentos encontrados parten tácitamente del reconocimiento de derechos en las GF, es decir, los abordan como sujetos de derechos, a pesar de que no se logró encontrar en el derecho internacional alguna norma positiva o consuetudinaria a través de la cual se reconozca la condición jurídica de sujetos de derecho a las GF, por ello, el planteamiento de esta investigación de considerar a las GF como sujetos de derechos y obligaciones.

\section{CONCLUSIONES}

Los miembros de las GF por concebir y los concebidos, al no ser sujetos de derechos y obligaciones, no pueden adquirir derechos subjetivos, lo que constituye una aporía, en tanto que la ley establece la obligación de dejarles recursos naturales suficientes y un ambiente sano para su existencia, pero ellos no pueden acceder a dicho derecho, por no adecuarse a la definición establecida por la ley según la 
cual solo pueden ser sujetos de derechos y obligaciones o tener personalidad jurídica los seres humanos nacidos vivos.

Por ende, las GF hoy todavía no tienen derecho frente a nosotros, de acuerdo al marco regulado por el Código Civil colombiano. Por eso es necesario reestructurar la definición de persona y personalidad jurídica, so pena de que se que haga inaplicable e inexigible esa obligación legal.

\section{CONSIDERACIONES FINALES}

El mandato consagrado en el artículo 3 de la Ley 99 de 1993 no es un derecho. Por ser ineficaz, por su falta de limites, ausencia de topes, falta de precisión y omisión de su exigibilidad, no cumple los requisitos de la obligación de que sea determinada o determinable.

Tienen derecho a la obligación creada por artículo 3 de la Ley 99 de 1993, los seres humanos nacidos. Se excluye a los demás seres vivos por no tener la calidad de sujetos de derechos y obligaciones.

Son los niños (GF) los responsables de su propio futuro y no les permitimos decidir sobre él.

Es necesario y urgente establecer políticas al crecimiento poblacional. Si continuamos con el índice de reproducción actual agotaremos la capacidad de la Tierra de mantenernos, por más tecnologia que tengamos; recordemos que ya desaparecieron sociedades humanas, por no respetar el ambiente.

Los niños de hoy son nuestros acreedores, ¿estamos prestos a pagarles y respetarles ese derecho?

Educar a los educadores y a nosotros los padres, para educar en el respeto a la vida, es decir, el respeto al ambiente.

Se debe modificar o adicionar el Código Civil en lo concerniente a la ampliación de la personalidad jurídica acorde a la definición de persona; son aptos para relaciones jurídicas todos los miembros de la especie humana nacidos o no.

\section{1. PROpuEstas}

El concepto de personalidad jurídica debe ser acorde con la realidad social, cultural y ecológica de la especie humana y el resto de seres vivos. Se debe reconocer como sujeto de derechos a las GF entendidas como los probables seres humanos que nacerán después de nosotros en un tiempo indefinido hacia el futuro.

El concepto de personalidad jurídica debe ser ampliado en el Código Civil, incorporando lo siguiente: "La personalidad jurídica se adquiere al nacer vivo y estar 
completamente separado del vientre materno, igualmente se reconoce personalidad jurídica a las GF, entendidas estas como la continuación de la especie humana en el futuro".

La Ley 99 de 1993, adicionada en el artículo 3, debe ser aclarada con un inciso que especifique lo siguiente: "Esta obligación de conservar y preservar los recursos naturales y un entorno sano, es obligatoria a partir de la vigencia de esta ley para la generación presente y para las GF, que se entiende al usar los RNR de tal manera que su tasa de regeneración sea superior a la tasa de uso".

Establecer una politica de crecimiento demográfico seria y acorde con la realidad social y ambiental del país.

Incrementar la educación y la conciencia ambiental en las instituciones educativas con énfasis en la básica primaria, haciéndola de una manera lúdica, investigativa e integradora.

Los mecanismos de participación ambiental deben ampliarse para todos los niños y jóvenes menores de 18 años, ya que estamos hablando y decidiendo sobre su vida, sobre lo que van a recibir, cuánto van recibir y cómo lo van a recibir.

\section{BibLIOGRAFÍA}

Delgado Schneider, Veronica Pía, "El principio de la protección legal de la vida y la salud del nasciturus”. Revista de Derecho Privado, Universidad Externado de Colombia, 12-13 (2007).

FOLADORI, Guillermo, "El comportamiento humano a la luz de las teorías biológicas de la evolución”, Revista Ludus Vitalis, VIII (14) (2000).

Herrera, Amílcar O., La larga jornada, la crisis nuclear y el destino biológico del hombre, México, Siglo XXI, 1981.

Hervada, Javier, ¿Qué es el derecho?, Bogotá, Editorial Temis, 2005.

Hinestrosa, Fernando, Teoría de las obligaciones, concepto, estructura, vicisitudes, Bogotá, Editorial Universidad Externado de Colombia, 2002.

LoREnz, Konrad, Ocho pecados mortales de la humanidad civilizada, Barcelona, Plaza y Janes, trad. de Manuel Vásquez, 1973.

Moliner, María, Diccionario de uso español, Buenos Aires, 2007.

Rousseau, Juan Jacobo, Emilio o de la educación, México, Porrúa, 13 ed., 1999.

SARTori, Giovanni y Gianni Mazzoleni, La Tierra explota, superpoblación y desarrollo, adrid, Taurus, trad. de Miguel Ángel Ruiz de Azúa, 2003.

274 Unesco, Declaración sobre las Responsabilidades de las Generaciones Actuales para con las Generaciones Futuras, 1997, en http://www.unesco.org/cpp/ sp/declaraciones/generaciones.htm 
VALENCIA IRAGorRI, María Alejandra, El delito ecológico en el derecho penal colombiano, Bogotá, Forum, 1995.

Valencia Zea, Arturo y Álvaro Ortiz Monsalve, Derecho Civil, t. I, Bogotá, Temis, 14 ed., 2008.

\section{JURISPRUDENCIA}

Código Civil colombiano, Bogotá, Legis, 22 ed., 2009.

Corte Constitucional, sentencia C-013 de 1997.

Corte Constitucional, sentencia C-355 de 2006.

Corte Constitucional, sentencia C-542 de 1993, M. P. Vladimiro Naranjo Mesa.

Ley 99 diciembre 22 de 1993. 
